Thus, the mode of inheritance of the $D / D$ translocation chromosome found in the family reported here is quite similar to what has been demonstrated by larger studies.

\section{Richard L. NEU, LyTt I. GARDNER, MARGARET L. WILLIAMS, and MATTHEW J. BARLOW*}

Genetic and Endocrine Unit, Deportment of Pediatrics, State University of New York, Upstate Medical Center, Syracuse, New York, USA

\section{REFERBNCES}

Cohen, M. M. (1971). The chromosomal constitution of 165 human translocations involving D group chromosomes identified by autoradiography. Annales de Génétique, 14, 87-96.

Dutrillaux, B. and Lejeune, J. (1970). Etude de la descendance des individus porteurs d'une translocation $\mathrm{t}(\mathrm{DqDq})$. Annales de Génétique, 13, 11-18.

Hamerton, J. L. (1968). Robertsonian translocations in man: evidence for prezygotic selection. Cytogenetics, 7, 260-276.

Hamerton, J. L. (1971). Human Cytogenetics, vol. I, p. 263. Academic Press, New York.

* Major Barlow was on assignment to the Department of Pediatrics, State University of New York, Upstate Medical Center, Syracuse, NY, from the Office of the Surgeon General, United States Army Medical Corps.

\title{
Chromosome Nomenclature
}

The nomenclature of human chromosomes has been standardized by a series of meetings in Denver, London, and Chicago. A report on the most recent meeting of the series which was held in Paris in September 1971 has been published* by the National Foundation of the USA. Authors are now requested to use the Paris nomenclature when submitting manuscripts. An annotation on the new nomenclature, which takes account of the banding patterns on chromosomes for the first time, will appear in the June issue of the fournal of Medical Genetics.

* Paris Conference (1971): Standardization in Human Cytogenetics. Birth Defects: Original Article Series, 8, pt. 7, 1972. The National Foundation-March of Dimes, New York. 